\title{
Mecanosintesis y efecto antimicrobiano de óxidos metálicos nanoestructurados
}

\section{Mechanosynthesis and antimicrobial effect of nanostructured metal oxides}

\author{
América Rosalba Vázquez-Olmos, ${ }^{*}$ Alejandro Luis Vega-Jiménez, ${ }^{* *}$ \\ Blanca Paz-Díaz*
}

\begin{abstract}
In this article we present what we have done on the mechanosynthesis of a series of nanostructured oxides formed by $\mathrm{CuO}, \mathrm{CuBi}_{2} \mathrm{O}_{4}, \mathrm{ZnO}, \mathrm{Mn}_{3} \mathrm{O}_{4}, \mathrm{Fe}_{2} \mathrm{O}_{3}, \mathrm{CuFe}_{2} \mathrm{O}_{4}, \mathrm{ZnFe}_{2} \mathrm{O}_{4}$ and $\mathrm{MgO}$, as well as a brief literature review on the applications of said oxides as antimicrobial agents. Despite the development of new antibiotics, some microorganisms become multiresistants, for this reason, new ways of combating them have been sought. The nanoparticles formed by metal oxides have turned out to be a new tool in the fight against diseases caused by microorganisms. Taking into account the future development and applications of nanostructured materials constituted by metal oxides, it is very important to develop clean, cheap synthesis methods that generate adequate quantities of them, under mild reaction conditions. In this sense, mechanosynthesis or mechanical activation could open new guidelines for obtaining new nanostructured materials with antimicrobial properties.
\end{abstract}

KEYWORDS: mechanosynthesis, nanostructures, antimicrobials.

RESUMEN: En este artículo presentamos lo que hemos realizado sobre la mecanosíntesis de una serie de óxidos nanoestructurados formados por $\mathrm{CuO}, \mathrm{CuBi}_{2} \mathrm{O}_{4}, \mathrm{ZnO}, \mathrm{Mn}_{3} \mathrm{O}_{4}, \mathrm{Fe}_{2} \mathrm{O}_{3}, \mathrm{CuFe}_{2} \mathrm{O}_{4}, \mathrm{Zn}$ $\mathrm{Fe}_{2} \mathrm{O}_{4}$ y $\mathrm{MgO}$, así como una breve revisión bibliográfica sobre las aplicaciones de dichos óxidos como agentes antimicrobianos. No obstante el desarrollo de nuevos antibióticos, algunos microrganismos se vuelven multirresistentes, por tal razón se han buscado nuevas formas de combatirlos. Las nanopartículas formadas por óxidos metálicos han resultado ser una nueva herramienta en la lucha contra las enfermedades causadas por microrganismos. Tomando en cuenta el futuro desarrollo y las aplicaciones de los materiales nanoestructurados constituidos por óxidos metálicos, es muy importante desarrollar métodos de síntesis limpios, baratos y que generen cantidades adecuadas de éstos en condiciones de reacción suaves. En ese sentido, la mecanosíntesis o bien la activación mecánica podrían abrir nuevas directrices hacia la obtención de nuevos materiales nanoestructurados con propiedades antimicrobianas.

PALABRAS CLAVE: mecanosíntesis, nanoestructuras, antimicrobianos.

Recibido: 19 de noviembre de 2017.

Aceptado: 27 de marzo de 2018.

* Universidad Nacional Autónoma de México, Instituto de Ciencias Aplicadas y Tecnología, Ciudad de México, México.

** Universidad Nacional Autónoma de México, Facultad de Odontología, Ciudad de México, México.

Autor para correspondencia: (dr.vegalex@gmail.com). 


\section{Introducción}

A partir del desarrollo en la ciencia de materiales, se han buscado nuevas formas terapéuticas para tratar las enfermedades de manera eficaz y segura. Según datos de la OMS, la resistencia a los antimicrobianos (RAM) pone en peligro la eficacia de la prevención y el tratamiento de una serie cada vez mayor de infecciones por virus, bacterias, hongos y parásitos. Además, supone una amenaza cada vez mayor para la salud pública mundial y requiere medidas por parte de todos los sectores del gobierno y la sociedad.

El éxito de la cirugía mayor y la quimioterapia cada vez se verá más comprometido en ausencia de antibióticos eficaces. Por otro lado, la prolongación de las enfermedades, la necesidad de más pruebas y la utilización de fármacos más caros aumentan el costo de la atención sanitaria a los pacientes con infecciones multirresistentes. Se estima que cada año cerca de 480,000 personas presentan tuberculosis multirresistente, y la farmacorresistencia empieza a complicar también la lucha contra el viH y el paludismo (World Health Organization, 2018).

Algunas de las potenciales ventajas de las nanopartículas (NPs), para luchar contra las enfermedades infecciosas causadas por microrganismos, es que no generan resistencia en éstos, pudiendo reducir los efectos secundarios en el paciente (Jan et al., 2014; Kalyani et al., 2015; Mamonova et al., 2015).

Sin embargo, es de considerar que falta mucha investigación para poder entender cómo actúan las NPs y así poder diseñar mejores terapias. Se ha visto que la actividad de las nanopartículas depende del tamaño y de la forma de las mismas; por lo que se requiere investigación activa de los materiales a escala nanométrica para llevar a cabo su diseño. En los últimos tiempos se ha realizado mucha ciencia básica y aplicada alrededor de diversos óxidos metálicos con diferentes formas y tamaños para su posible aplicación en catálisis, como semiconductores, sensores, en liberación controlada de fármacos y como agentes antimicrobianos.

Las propiedades físicas y químicas de las NPs de óxidos metálicos permiten su interacción con sistemas biológicos, lo cual se ha vuelto de vital importancia debido a la creciente resistencia de bacterias sobre todo Gram-negativas. Dentro de estas propiedades se encuentran la forma, tamaño, rugosidad, potencial zeta y recubrimientos, entre otros (Mamonova et al., 2015; Wang et al., 2017). La actividad antimicrobiana que presentan las nanoestructuras de dichos óxidos podría tener una aplicación a nivel terapéutico principalmente, pero también puede extenderse a la industria alimenticia, a la purificación de agua y a la industria textil.

\section{Nanopartículas de óxidos metálicos}

Los óxidos metálicos en general y en particular los óxidos formados por metales de transición son compuestos con propiedades electrónicas únicas, la 
mayoría de los fenómenos magnéticos involucran a este tipo de óxidos. Además, sus nanoestructuras, debido a sus dimensiones de unos cuantos nanómetros y a su gran superficie específica, resultan candidatos ideales para interactuar con las bacterias. De tal manera, las NPs de óxidos metálicos se han convertido en una alternativa para combatir bacterias resistentes a la acción de antibióticos (Raghunath y Perumal, 2017). En particular, se ha informado que las NPs de óxido de titanio $\left(\mathrm{TiO}_{2}\right)$, óxido de cinc $(\mathrm{ZnO})$, óxido cúprico $(\mathrm{CuO})$, la magnetita $\left(\mathrm{Fe}_{3} \mathrm{O}_{4}\right)$ y el óxido de magnesio $(\mathrm{MgO})$ presentan importantes propiedades antimicrobianas, las cuales dependen en gran medida de su composición química, forma y tamaño.

Se ha informado sobre diversas teorías alrededor del efecto bactericida de los óxidos metálicos nanoestructurados, que a continuación se describen (figura 1), (Hemeg, 2017; Lemire et al., 2013; Raghunath y Perumal, 2017; Stankic et al., 2016; Wang et al., 2017):

- Estrés oxidativo, formación de especies reactivas de oxígeno (ERO). Son un conjunto de moléculas reactivas producidas en algunos procesos metabólicos en los que participa el oxígeno: el anión superóxido $\mathrm{O}_{2}-$ que es un potente agente oxidante muy reactivo con el agua. El peróxido de hidrógeno $\mathrm{H}_{2} \mathrm{O}_{2}$ y el radical hidroxilo $(\mathrm{OH})$ que es el más reactivo, ya que aceptando un electrón más, da lugar a una molécula de agua. Las NPs de óxidos metálicos son capaces de producir distintas especies reactivas de oxígeno, pueden participar en distintos tipos de reacciones en las que pueden sufrir procesos de oxidación o reducción. Las ERO pueden producir efectos nocivos sobre las células como daños en el ADN, daños producidos por oxidación de ácidos grasos poliinsaturados y de aminoácidos. La alteración del balance en los mecanismos de producción y eliminación de las $E R O$, en favor de la producción, origina el estado de estrés oxidativo en la célula. Las NPs de $\mathrm{MgO}$ pueden generar $\mathrm{O}_{2}-$, mientras que las NPs de $\mathrm{ZnO}$ pueden generar $\mathrm{H}_{2} \mathrm{O}_{2}$ y $\mathrm{OH}$ pero no $\mathrm{O}_{2}-$. Por otro lado, las NPs de $\mathrm{CuO}$ pueden producir los cuatro tipos de oxígeno reactivo. $\mathrm{El}_{2}$ y el $\mathrm{H}_{2} \mathrm{O}_{2}$ causan reacciones de estrés menos agudas y pueden ser neutralizados por antioxidantes endógenos, como las enzimas superóxido y la catalasa, mientras que el $\mathrm{OH}$ y el $\mathrm{O}_{2}$ pueden conducir a la muerte microbiana aguda.

- Daño en pared-membrana celular por interacción electrostática y acumulación. Los grupos electronegativos de los polisacáridos en la membrana bacteriana son sitios de atracción de cationes metálicos. La diferencia de carga entre membranas bacterianas y las NPs de óxidos metálicos conduce a la atracción electrostática y así se acumulan en la superficie de la bacteria alterando la estructura y la permeabilidad de la membrana celular. Las bacterias Gram-negativas tienen una mayor carga negativa que las bacterias Gram-positivas y 
por lo tanto la interacción electrostática será más fuerte en las cepas Gram-negativas. Los poros de las membranas se encuentran en el orden de nanómetros, por lo tanto entre menor sea el tamaño de partícula y mayor es el área de superficie, mayor es la eficacia de los óxidos metálicos nanoestructurados. De la misma manera los cationes extraídos de las NPs de los óxidos metálicos y su acumulación en pared celular, crean fosas en ella, llevando a un cambio en la permeabilidad debido a la liberación sostenida de lipopolisacáridos, proteínas de la membrana y factores intracelulares. Además, se ha vinculado este mecanismo con la interrupción de la replicación del adenosín trifosfato (ATP) y del ácido desoxirribonucléico (ADN) de la bacteria, llevándola a su muerte. Un estudio señala que la acción de las NPs depende de los componentes y la estructura de la célula bacteriana. Se mencionó por ejemplo, que la acción antimicrobiana de $\mathrm{ZnO}$ es más efectiva en bacterias Gram-positivas. Los componentes peculiares de las bacterias Gram-negativas, como los lipopolisacáridos (LPS), pueden prevenir la adhesión de las NP de $\mathrm{ZnO}$ a la barrera de las células bacterianas y regular el flujo de iones dentro y fuera de la membrana celular bacteriana.

- Pérdida de homeostasis por iones metálicos. El balance de elementos metálicos es esencial para la supervivencia microbiana, ya que regula las funciones metabólicas al ayudar a las coenzimas, cofactores y catalizadores. Cuando las bacterias tienen un exceso de metales o iones metálicos, habrá un desorden en las funciones metabólicas. Los iones metálicos se unen con el ADN y alteran la naturaleza helicoidal mediante enlaces cruzados entre y dentro de las cadenas de ADN. Los iones metálicos neutralizan las cargas en lps y aumentan la permeabilización de la membrana externa. Reportes señalan que las NPs de $\mathrm{TiO}_{2}$ pueden adherirse a la superficie de las células bacterianas liberando iones y dañando la composición y estructura de la membrana celular, interfiriendo con la función de la membrana celular y causando la fuga de contenido celular, resultando en la muerte bacteriana. Nanopartículas que contienen $\mathrm{Fe}^{(2+)} / \mathrm{Fe}^{(3+)}$ también puede causar la descomposición de las células bacterianas debido a la difusión de iones metálicos generando grandes cantidades de radicales hidroxilo y la difusión en las células bacterianas. Otros estudios señalan que las NPs de óxidos metálicos pueden liberar lentamente iones metálicos a través de adsorción, disolución e hidrólisis. Dichos iones son tóxicos y abrasivos para las bacterias y, por lo tanto, lisan las células.

- Disfunción de proteínas y enzimas. La disfunción de la proteína es otro modo de actividad antibacteriana exhibida por NPs de óxidos metálicos. Los iones metálicos catalizan la oxidación de las cadenas laterales de aminoácidos dando como resultado carbonilos unidos a 
proteínas. Los niveles de carbonilación dentro de la molécula de proteína sirven como marcador para el daño oxidativo de la proteína. Esta carbonilación de proteínas conducirá a la pérdida de la actividad catalítica en el caso de las enzimas, lo que finalmente desencadena la degradación de las proteínas. Además, estos iones reaccionan con los grupos -SH de muchas proteínas y enzimas y los vuelven inactivos. Un estudio señala que las NPs de $\mathrm{CuO}$ causaron alteración significativa de expresión de proteínas involucradas en el metabolismo del nitrógeno, la transferencia de electrones y el transporte de sustancias.

- Genotoxicidad e inhibición de la señal de transducción. Debido a sus propiedades eléctricas, las NPs de óxidos metálicos interactúan con los ácidos nucleicos, en particular el ADN genómico y el plasmídico. Suprimen la división celular de los microbios al alterar los procesos de replicación del ADN cromosómico y del plásmido. Se sabe que la transducción de señales en las bacterias se ve afectada por las NPs de óxidos metálicos. La fosfotirosina es un componente esencial del mecanismo de transducción de señales en bacterias. Estas nanopartículas desfosforilan los residuos de fosfotirosina, lo que inhibe la transducción de señales y, en última instancia, obstruye el crecimiento de bacterias. Estudios señalan que las NPs de $\mathrm{MgO}$ pueden alterar la expresión de muchas proteínas metabólicas, incluida la regulación de una proteína débil de unión a ésteres de tiamina y riboflavina, y la regulación de una proteína asignada a la ruta crítica del metabolismo celular bacteriano, lo que resulta en una reducción de la actividad metabólica celular, lo que sugiere que las NPs regulan los procesos metabólicos de las bacterias actuando sobre las proteínas diana. Las NPs de $\mathrm{CuO}$ pueden regular la expresión de proteínas relacionadas con el metabolismo de nitrógeno bacteriano e inhibir significativamente la actividad de la nitrato reductasa y la reductasa de nitrito.

Finalmente, también es importante considerar que los cationes presentes en la superficie de las NPs formadas por óxidos metálicos, son ácidos de Lewis con valencias insaturadas que podrían formar enlaces de tipo covalente dativo, con bases de Lewis (grupos nitrogenados y oxigenados) presentes en los aminoácidos y polisacáridos constituyentes de la pared celular. Dicha interacción también podría generar la lisis de la pared celular.

Por todo lo anterior, es importante tener en cuenta que existen diversos mecanismos que pueden estar involucrados en la actividad antimicrobiana de las NPs de los óxidos metálicos.

Para preparar óxidos nanocristalinos con tamaños y formas controlados se han empleado diferentes métodos de síntesis, los cuales involucran entre otros, el método sol-gel (Fernández-Osorio et al., 2007; Fernández-Osorio 
FIGURA 1. Teorías del efecto bactericida de los óxidos metálicos nanoestructurados.

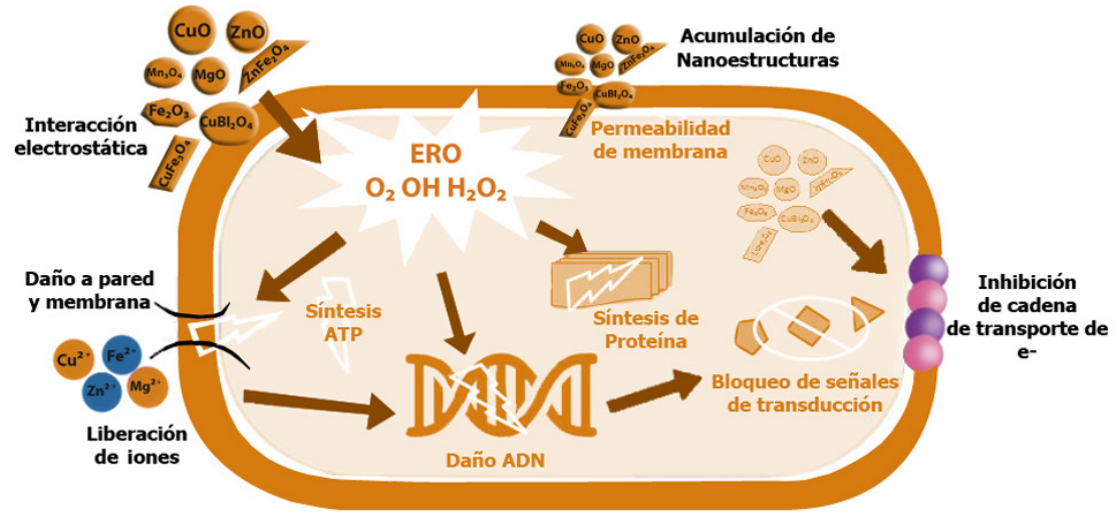

Fuente. Imagen diseñada con base en Lemire I. A. et al., 2013; Slavicas S. et al., 2016; Hemeg H. A., 2017; Raghunath A. et al., 2017 y Wang L. et al., 2017.

et al., 2011), el método coloidal (Vázquez-Olmos et al., 2005a; VázquezOlmos et al., 2005b; Vázquez-Olmos et al., 2016; Velasco-Arias et al., 2008), así como procesos hidrotérmicos (Fernández-Osorio et al., 2009) métodos de coprecipitación (Fernández-Osorio et al., 2015), y cada vez más, métodos mecanoquímicos (Vázquez-Olmos et al., 2008; Vázquez-Olmos et al., 2016; Vázquez-Olmos et al., 2014).

\section{Mecanosíntesis}

El término mecanoquímica se refiere a las reacciones químicas que involucran reactivos en cualquier estado de agregación, pero comúnmente se usa para reacciones sólido-sólido, en donde la energía necesaria para llevar a cabo la reacción, involucra un proceso o tratamiento mecánico (Heinicke et al., 1984). Este método se ha empleado en los últimos años para sintetizar materiales a partir de reactivos en estado sólido, que a temperaturas habituales de trabajo no muestran la reactividad necesaria para su formación, o bien, para la preparación de compuestos que, en condiciones normales de presión y temperatura, son metaestables o no pueden ser obtenidos por métodos de síntesis convencionales. Se ha comprobado que la activación mecanoquímica de sólidos cambia su reactividad, debido a la acumulación de defectos en situación de no equilibrio, lo cual repercute en la disminución de las energías de activación para que se lleven a cabo algunas reacciones químicas (Gaffet et al., 1999). La acción mecánica que se ejerce sobre los reactivos permite llevar a cabo una verdadera reacción química (mecanosíntesis) que hace posible obtener nuevos compuestos, con dimensiones nanométricas. En general, la energía mecánica que se aporta a los reactivos en estado sólido puede acumularse en la deformación plástica de los cristales, produciendo defectos 
cristalinos que, en consecuencia, producen regiones de especial reactividad química que facilitan el desarrollo de los procesos en fase sólida. Según el sistema y las condiciones de activación, pueden producirse reacciones en fase sólida durante el tratamiento mecánico a temperatura ambiente y/o pueden generarse cambios estructurales, reduciéndose la temperatura necesaria de ciertas reacciones.

La mecanosíntesis ha despertado el interés de diversos grupos de investigación en nanomateriales principalmente debido a su sencillez y su bajo impacto ambiental.

En nuestro grupo de investigación hemos llevado a cabo la obtención de nanoestructuras de diferentes óxidos metálicos por un proceso que involucra la molienda de las sales metálicas de partida, generalmente cloruros o acetatos, en presencia de una base $(\mathrm{NaOH}$ o $\mathrm{KOH})$, el producto obtenido se lava con agua y posteriormente con acetona, separando en cada ocasión por centrifugación. En algunos casos no ha sido necesario llevar a cabo un tratamiento térmico posterior, y en otros, se han llevado a cabo tratamientos térmicos por 400,600 y $800^{\circ} \mathrm{C}$, durante 2 horas. En la figura 2 se presenta el esquema general de síntesis de las NPs de diferentes óxidos metálicos obtenidos en nuestro grupo de investigación.

Todas las nanoestructuras han sido caracterizadas por difracción de rayos-X en polvo, espectroscopías de absorción electrónica UV-visible, infrarrojo por transformada de Fourier (FTIR), dispersión Raman, resonancia paramagnética electrónica (EPR), microscopía electrónica de transmisión (TEM) así como microscopía electrónica de transmisión de alta resolución (HRTEM). La caracterización magnética de dichas nanoestructuras también se ha llevado a cabo. En la figura 3 se presentan algunas micrografías obtenidas

FIGURA 2. Esquema general de la metodología llevada a cabo para obtener diferentes nanoestructuras de óxidos metálicos.

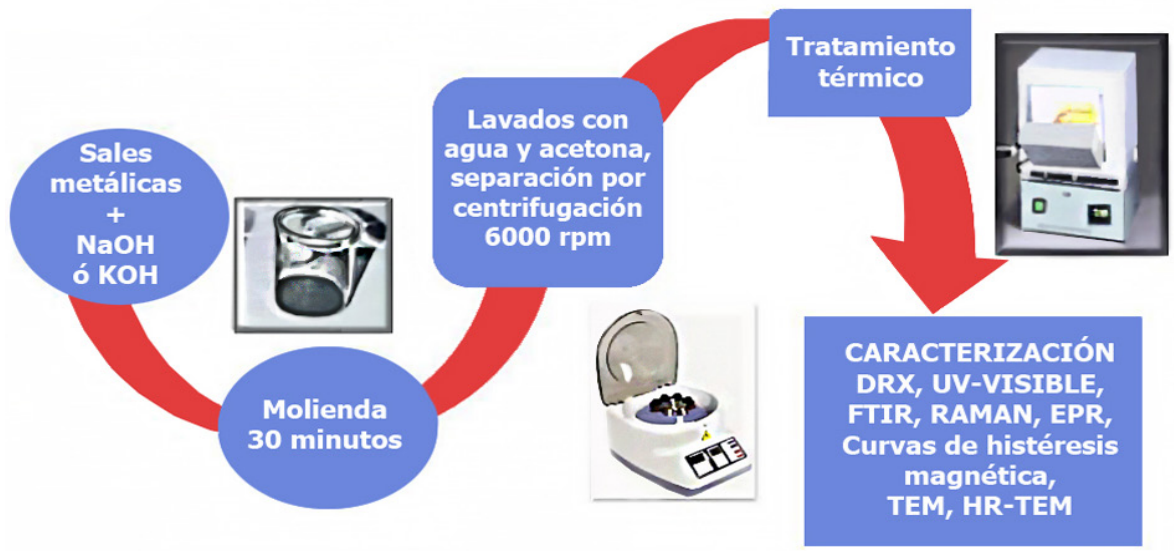

Fuente. Imagen de metodología proporcionada por América Vázquez Olmos. 
FIGURA 3. Micrografias obtenidas por HR-TEM, de algunos de los óxidos nanoestructurados obtenidos por mecanosíntesis.

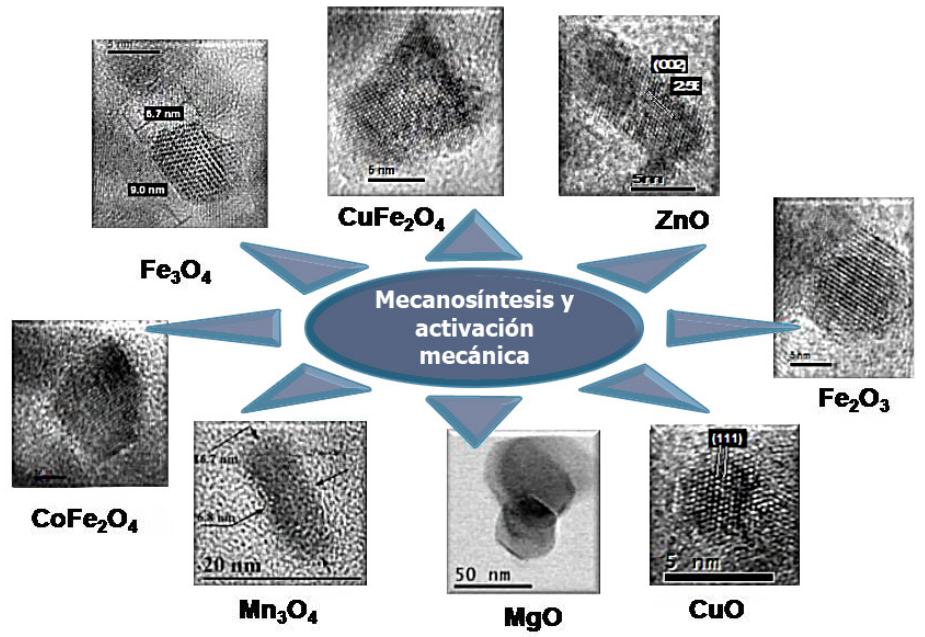

Fuente. Imágenes de América Vázquez Olmos y colaboradores.

por HR-TEM de las NPs de los óxidos obtenidos en nuestro grupo de investigación.

A continuación se presenta una breve revisión sobre las propiedades antimicrobianas, informadas en la literatura, de los siguientes sistemas nanoestruturados; $\mathrm{CuO}, \mathrm{CuBi}_{2} \mathrm{O}_{4}, \mathrm{ZnO}, \mathrm{Mn}_{3} \mathrm{O}_{4}, \mathrm{Fe}_{2} \mathrm{O}_{3}, \mathrm{CuFe}_{2} \mathrm{O}_{4}, \mathrm{ZnFe}_{2} \mathrm{O}_{4}$ y $\mathrm{MgO}$, los cuales han sido obtenidos en nuestro grupo de investigación, empleando la aproximación mecanoquímica.

\section{Nanoestructuras de CuO}

El cobre es un conocido agente antimicrobiano desde hace varios siglos. Se ha utilizado de diversas formas para evitar la propagación de diferentes enfermedades desde el Egipto antiguo, pasando por el Imperio romano y hasta en la Segunda Guerra Mundial (Prado et al., 2012; Vincent et al., 2016). Sin embargo, el metal no sólo puede ser tóxico para los microrganismos, también para los humanos y el ambiente. Tomando en cuenta su toxicidad, se han estudiado de manera intensiva un gran número de materiales basados en el cobre, para poder controlar su liberación al medio ambiente (Prado et al., 2012). En ese sentido, el óxido cúprico $\mathrm{CuO}$ ha resultado ser un compuesto muy popular debido a su estabilidad, larga vida útil, así como a sus diversas aplicaciones. El $\mathrm{CuO}$ se encuentra en la naturaleza como el mineral tenorita, cristaliza en forma monoclínica y es un semiconductor tipo $\mathrm{p}$, con un band gap estrecho de $1.2 \mathrm{eV}$.

En los últimos años las nanopartículas y nanocompositos de $\mathrm{CuO}$ han sido ampliamente estudiados por su efecto antimicrobiano y son el sistema 
más utilizado a nivel comercial; en textiles, como biocidas y en pinturas, debido a dicho efecto (Hou et al., 2017). Se ha probado que tiene efecto antimicrobiano frente a cepas de Escherichia coli, Enterococcus faecalis, Pseudomonas aeruginosa, Klebsiella pneumoniae, Staphylococcus aureus y Bacillus subtilis, entre otras (Katwal et al., 2015); mostrando una actividad de 20 a 90 veces mejor que la observada en $\mathrm{CuO}$ en bulk (Hou et al., 2017). Diferentes estudios llevados a cabo para determinar el mecanismo de acción de las NPs de $\mathrm{CuO}$, revelan que éstas interactúan con la pared celular bacteriana, favoreciéndose la penetración de éstas y a su interacción con el material genético. Esto genera una serie de daños y desorganización celular, llevando a la muerte de la bacteria. La interacción que se lleva a cabo dependerá del diámetro de las nanopartículas, la modificación de su superficie, la vía de exposición y la posible liberación de iones $\mathrm{Cu}^{2+}$ (Hou et al., 2017).

\section{Nanoestructuras de $\mathrm{CuBi}_{2} \mathrm{O}_{4}$}

El óxido de cobre y bismuto, $\mathrm{CuBi}_{2} \mathrm{O}_{4}$, se encuentra en la naturaleza como el mineral Kusachiita y es un material semiconductor tipo p, con una energía de brecha prohibida o band gap de $1.5-1.8 \mathrm{eV}$, cristaliza en forma tetragonal. Hasta ahora las principales aplicaciones del $\mathrm{CuBi}_{2} \mathrm{O}_{4}$ son en la degradación de algunos colorantes contaminantes del agua y como microbicida (Elaziouti et al., 2016; Wen-da et al., 2016; Zhu et al., 2016). Un estudio reciente señala que microestructuras de $\mathrm{CuBi}_{2} \mathrm{O}_{4}$ demostraron tener una buena acción fotocatalítica en la conversión de energía y tener un buen efecto antimicrobiano frente a cepas de E. coli, observándose una reducción del $93.3 \%$ en su densidad óptica después de una irradiación de luz led $\left(10 \mathrm{~mW} / \mathrm{cm}^{2}\right)(Z h u$ et al., 2016). Las NPs de $\mathrm{CuBi}_{2} \mathrm{O}_{4}$ resultan un material prometedor como agente antimicrobiano.

\section{Nanoestructuras de ZnO}

El óxido de zinc $\mathrm{ZnO}$ es un compuesto ampliamente conocido por sus propiedades antimicrobianas. Es un semiconductor tipo $\mathrm{n}$ con un band gap de $3.3 \mathrm{eV}$ cuya estructura cristalina puede ser hexagonal (tipo wurtzita) o cúbica (blenda de zinc), siendo la wurtzita la más común. Las NPs de ZnO pueden adoptar una gran variedad de morfologías como son; anillos, hélices, cinturones, alambres y flores, entre otros (Król et al., 2017; Wang, 2004). Las nanopartículas de $\mathrm{ZnO}$ actúan como agentes antimicrobianos a través de diversos mecanismos, siendo el más importante la generación de especies reactivas de oxígeno (Kaftelen et al., 2012) al interior de la célula. Se ha propuesto que las NPs de $\mathrm{ZnO}$ pueden actuar para generar la muerte celular, o bien, como fuente de iones de $\mathrm{Zn}^{2+}$, cuyo exceso genera una alteración del metabolismo celular. Algunas especies reportadas como susceptibles a las NPs de $\mathrm{ZnO}$ son; S aureus, S. epidermidis, Streptococcus pyogenes, Enterococcus faecalis (Santhoshkumar et al., 2017), Bacillus subtilis, Escherichia coli y Klebsiella pneumoniae (Król et al., 2017). Estas bacterias son de interés clínico, ya 
que pueden generar infecciones intra-hospitalarias ocasionando cuadros infecciosos graves y algunas cepas se encuentran en el agua o comida, por lo que las NPs de $\mathrm{ZnO}$ pueden tener una posible aplicación en diversas industrias.

\section{Nanoestructuras de $\mathrm{Mn}_{3} \mathrm{O}_{4}$}

El tetróxido de trimanganeso, $\mathrm{Mn}_{3} \mathrm{O}_{4}$, es un óxido mixto de manganeso ( $\mathrm{Mn}(\mathrm{II}) \mathrm{Mn}$ (III)2O4) que cristaliza en forma cúbica y es una espinela normal. Se presenta en la naturaleza como el mineral hausmanita. Las propiedades antimicrobianas de las NPs de $\mathrm{Mn}_{3} \mathrm{O}_{4}$ han sido poco estudiadas. Se ha informado un efecto moderado de dichas NPs frente a cepas del Vibrio cholerae, Shigella sp., Salmonella sp., y Escherichia coli (Chowdhury et al., 2009). Por otro lado, se ha evaluado el efecto de las NPs de $\mathrm{Mn}_{3} \mathrm{O}_{4}$ frente a cepas de $E$. coli y $S$. aureus a través de ensayos de microdilución (Azhir et al., 2015). Los resultados de las concentraciones mínimas inhibitorias (CMI) indicaron que la bacteria $E$. coli fue más sensible a la acción de las NPs de $\mathrm{Mn}_{3} \mathrm{O}_{4}$. Se observó que el efecto inhibitorio se incrementa conforme aumenta la concentración de NPs de $\mathrm{Mn}_{3} \mathrm{O}_{4}$, lo cual podría deberse a las diferentes características de las superficies de las células bacterianas y su interacción con las NPs, es decir, el mecanismo de acción podría enfocarse en la pared de la membrana bacteriana.

\section{Nanoestructuras de $\mathrm{Fe}_{2} \mathrm{O}_{3}$}

El óxido de hierro (III) es un óxido muy estable, que cristaliza en forma hexagonal y se encuentra en la naturaleza como el mineral hematita $\alpha-\mathrm{Fe}_{2} \mathrm{O}_{3}$. Las nanoestructuras de este óxido adoptan diferentes formas como son; nanoalambres, nanotubos, nanoesferas, etcétera (Tadic et al., 2017). Si bien su síntesis ha sido ampliamente estudiada, no así su posible efecto antimicrobiano. Se ha informado sobre su efecto bactericida contra E. coli y $S$. aureus, en donde se observa un incremento de tal efecto, conforme aumenta la concentración de las NPs de $\mathrm{Fe}_{2} \mathrm{O}_{3}$ (Rufus et al., 2016). También se ha visto un efecto bactericida a $P$. aeruginosa con una concentración mínima inhibitoria de 0.06mg/L (Irshad et al., 2017). Otro estudio informa sobre la actividad bactericida de la hematita nanoestructurada contra una variedad de bacterias Gram-positivas y Gram-negativas; $P$. aeruginosa, S. aureus, K. pneumoniae, Lysinibacillus sphaericus y Bacillus safensis (Muthukumar et al., 2017); proponiendo incluso algunos mecanismos de acción dependiendo de la actividad observada en cada etapa del crecimiento de la bacteria en cuestión. Incluso se ha llegado a determinar un efecto bactericida de NPs de $\mathrm{Fe}_{2} \mathrm{O}_{3}$ contra $S$. epidermidis (Groiss et al., 2017).

A partir de sus propiedades se ha propuesto su posible aplicación en la remediación del ambiente y del agua, así como en el área biomédica, debido a los diferentes estudios de citotoxicidad que se han llevado a cabo. (Tadic et al., 2017). 


\section{Nanoestructuras de ferrita de cobre $\left(\mathrm{CuFe}_{2} \mathrm{O}_{4}\right)$}

y de ferrita de cinc $\left(\mathrm{ZnFe}_{2} \mathrm{O}_{4}\right)$

Hasta ahora no se ha llevado a cabo mucha investigación alrededor de la actividad antimicrobiana de ferritas, a no ser por la ferrita de hierro, la magnetita $\mathrm{Fe}_{3} \mathrm{O}_{4}$ (Kefeni et al., 2017). Sin embargo, ya que se ha observado que los óxidos de hierro $\left(\mathrm{Fe}_{3} \mathrm{O}_{4}, \mathrm{Fe}_{2} \mathrm{O}_{3}\right)$, de cobre $(\mathrm{CuO})$ y de cinc $(\mathrm{ZnO})$ presentan actividad antimicrobiana es factible pensar que la ferrita de cobre, $\mathrm{CuFe}_{2} \mathrm{O}_{4}$ y la ferrita de cinc $\mathrm{ZnFe}_{2} \mathrm{O}_{4}$, puedan presentar actividad antimicrobiana frente a cepas de diferentes bacterias Gram-positivas y Gram-negativas.

En particular NPs de $\mathrm{ZnFe}_{2} \mathrm{O}_{4}$ han mostrado buena actividad antimicrobiana contra $S$. aureus, $B$. subtilis y E. coli, siendo su actividad muy comparable con la estreptomicina (Mandal et al., 2016). Por otro lado, no se encuentran informes en la literatura acerca de la actividad antimicrobiana de NPs de $\mathrm{CuFe}_{2} \mathrm{O}_{4}$. Debido a la falta de información en relación con estas ferritas, y en especial a la de cobre, es que se quiere llevar a cabo el estudio de su posible actividad antimicrobiana. Las NPs de dichas ferritas podrían servir como acarreadores de iones metálicos de cobre o de cinc, presentando efectos tóxicos contra las bacterias.

\section{Nanoestructuras de $\mathrm{MgO}$}

El óxido de magnesio $\mathrm{MgO}$, se presenta en la naturaleza como el mineral periclasa (Rankin, 2009). Se ha informado sobre la actividad antibacteriana del $\mathrm{MgO}$ contra bacterias Gram-positivas y Gram-negativas. Se ha informado que la actividad antimicrobiana del $\mathrm{MgO}$ micrométrico, se debe a la presencia de oxígeno activo como superóxido $\left(\mathrm{O}_{2}-\right)$, en la superficie de las partículas de MgO (Sawai et al., 2000; Sawai, 2003; Sawai y Yoshikawa, 2004). Por otro lado, se ha propuesto que las NPs de MgO pueden dañar la membrana celular causando la pérdida de contenidos intracelulares y provocando la muerte de las células bacterianas (Jin y He, 2011). Se ha atribuido la generación de especies reactivas de oxígeno a la alcalinidad de la superficie de las NPs de MgO (Yamamoto et al., 2010). Se ha evaluado la actividad antibacteriana de NPs de $\mathrm{MgO}$ contra bacterias Gram-negativas; E. coli y P. aeruginosa (500 y $1000 \mu \mathrm{g} / \mathrm{mL})$ y en una bacteria Gram-positiva; S. aureus $(1000 \mu \mathrm{g} /$ $\mathrm{mL}$ ) (Krishnamoorthy et al., 2012). Las NPs de MgO potenciaron la peroxidación de lípidos inducida por ultrasonido en la membrana liposomal. En este caso el mecanismo de acción podría estar asociado con la presencia de defectos, o bien a la falta de oxígeno en la superficie de la nanopartícula, conduciendo a la peroxidación lipídica y la generación de especies reactivas de oxígeno (Krishnamoorthy et al., 2012). El efecto antibacteriano y el mecanismo de acción de NPs de MgO contra cepas de Campylobacter jejuni, E. coli y Salmonella enteritidis ha sido estudiado(He et al., 2016). En este caso se observó que la permeabilidad de la membrana de las bacterias, después de la exposición a las NPs de MgO, se vio comprometida, encontrándose la presencia de peróxido de hidrógeno que subsecuentemente causaría muerte celu- 
lar. Cepas de P. aeruginosa y $S$. aureus frente a NPs de MgO mostraron una mayor zona de inhibición en $S$. aureus que en $P$. aeruginosa (Bindhu et al., 2016). Basándose en trabajos previos, los autores señalan que la acción bactericida de las nanopartículas de $\mathrm{MgO}$ se puede deber a la unión del oxígeno superficial a las bacterias. A medida que aumenta el área superficial de las partículas, aumenta la concentración de iones oxígeno en la superficie, lo que da como resultado una destrucción más efectiva de la membrana citoplásmica y de la pared celular de las bacterias.

\section{Conclusión}

La búsqueda constante de nuevas formas terapéuticas para tratar, e incluso prevenir infecciones, es un campo de investigación muy atractivo. Las nanopartículas, y en especial las de óxidos metálicos, han empezado a dar resultado como una buena alternativa para luchar contra diferentes microrganismos multirresistentes causantes de diversas enfermedades. Sin embargo, los mecanismos por los que actúan dichas nanoestructuras aún no han sido completamente dilucidados.

Tomando en cuenta el futuro desarrollo y las aplicaciones de los materiales nanoestructurados constituidos por óxidos metálicos, es muy importante desarrollar métodos de síntesis limpios, baratos y que generen cantidades adecuadas de éstos, en condiciones de reacción suaves.

Nuestra dependencia hacia los disolventes, se vuelve cada vez más insostenible ya que es un desperdicio de materiales de origen fósil. Por ejemplo el $85 \%$ de los productos químicos utilizados en la industria farmacéutica son disolventes y aunque se reciclan, la recuperación en el mejor de los casos es del 50 al 80\%. Además, se involucra dinero y energía para llevar a cabo la depuración y el reciclaje.

En ese sentido la mecanosíntesis o bien la activación mecánica podrían abrir nuevas directrices hacia la obtención de nuevos materiales nanoestructurados con propiedades antimicrobianas.

\section{Referencias}

Azhir, E., Etefagh, R., Mashreghi, M., Pordeli, P. (2015). Preparation, characterization and antibacterial activity of manganese oxide nanoparticles. Physical Chemistry Research, 3(3): 197-204. https://doi.org/10.22036/PCR.2015.9329

Bindhu, M., Umadevi, M., Micheal, M. K., Arasu, M. V., Al-Dhabi, N. A. (2016). Structural, morphological and optical properties of $\mathrm{MgO}$ nanoparticles for antibacterial applications. Materials Letters, 166: 19-22.

https://doi.org/10.1016/j.matlet.2015.12.020

Chowdhury, A.-N., Azam, M. S., Aktaruzzaman, M., Rahim, A. (2009). Oxidative and antibacterial activity of $\mathrm{Mn}_{3} \mathrm{O}_{4}$. Journal of hazardous materials, 172(2): 1229-1235. https://doi.org/10.1016/j.jhazmat.2009.07.129 
Elaziouti, A., Laouedj, N., Bekka, A. (2016). Synergetic effects of Sr-doped $\mathrm{CuBi}_{2} \mathrm{O}_{4}$ catalyst with enhanced photoactivity under UVA-light irradiation. Environmental Science and Pollution Research, 23(16): 15862-15876.

https://doi.org/10.1007/s11356-015-4946-0

Fernández-Osorio, A., Vázquez-Olmos, A., Sato-Berru, R., Escudero, R., Fernández-Osorio, A., et al. (2009). Hydrothermal synthesis of co3o4 nanooctahedra and their magnetic properties. Rev Adv Mater Sci, 22: 60-66.

Fernández-Osorio, A., Castañeda-Guzmán, R., Vázquez-Olmos, A., Huanosta-Tera, A. (2007). Photoacoustic and dielectric study of lead zirconate titanate nanoparticles.Ferroelectrics 361(1): 92-104. https://doi.org/10.1080/00150190701729482

Fernández-Osorio, A., Jiménez-Segura, M., Vázquez-Olmos, A., Sato-Berru, R. (2011). Turquoise blue nanocrystalline pigment based on Li $1.33 \mathrm{Ti} 1.66 \mathrm{O} 4$ : Synthesis and characterization. Ceramics International, 37(5): 1465-1471. https://doi.org/10.1016/j.ceramint.2010.11.015

Fernández-Osorio, A., Rivera, C., Vázquez-Olmos, A., Chávez, J. (2015). Luminescent ceramic nano-pigments based on terbium-doped zinc aluminate: Synthesis, properties and performance. Dyes and Pigments, 119: 22-29.

https://doi.org/10.1016/j.dyepig.2015.03.021

Gaffet, E., Bernard, F., Niepce, J.-C., Charlot, F., Gras, C., Le Caër, G. et al. (1999). Some recent developments in mechanical activation and mechanosynthesis. Journal of materials chemistry, 9(1):305-314. https://doi.org/10.1039/a804645j

Groiss, S., Selvaraj, R., Varadavenkatesan, T., Vinayagam, R. (2017). Structural characterization, antibacterial and catalytic effect of iron oxide nanoparticles synthesised using the leaf extract of Cynometra ramiflora. Journal of Molecular Structure, 1128: 572-578. https://doi.org/10.1016/j.molstruc.2016.09.031

He, Y., Ingudam, S., Reed, S., Gehring, A., Strobaugh, T. P., Irwin, P. (2016). Study on the mechanism of antibacterial action of magnesium oxide nanoparticles against foodborne pathogens. Journal of nanobiotechnology, 14(1): 54.

https://doi.org/10.1186/s12951-016-0202-0

Heinicke, G., Hennig, H. P., Linke, E., Steinike, U., Thiessen, K. P., Meyer, K. (1984). Tribochemistry Akademie-Verlag, Berlin 1984495 S., 329 Abb., 106 Tab. Preis: 98,-M. Crystal Research and Technology, 19(11): 1424-1424.

https://doi.org/10.1002/crat.2170191103

Hemeg, H. A. (2017). Nanomaterials for alternative antibacterial therapy. International journal of nanomedicine: 12: 8211. https://doi.org/10.2147/IJN.S132163

Hou, J., Wang, X., Hayat, T., Wang, X. (2017). Ecotoxicological effects and mechanism of $\mathrm{CuO}$ nanoparticles to individual organisms. Environmental Pollution: 221: 209-217. https://doi.org/10.1016/j.envpol.2016.11.066

Irshad, R-, Tahir, K-, Li, B-, Ahmad, A-, Siddiqui, A. R., Nazir, S. (2017). Antibacterial activity of biochemically capped iron oxide nanoparticles: A view towards green chemistry. Journal of Photochemistry and Photobiology B: Biology, 170: 241-246. https://doi.org/10.1016/j.jphotobiol.2017.04.020

Jan, T., Iqbal, J., Ismail, M., Badshah, N., Mansoor, Q., Arshad, A. et al. (2014). Synthesis, physical properties and antibacterial activity of metal oxides nano- 
Mundo Nano | ARTículos | www.mundonano.unam.mx

11(21), 29-44, julio-diciembre 2018 | http://dx.doi.org/10.22201/ceiich.24485691e.2018.21.62545

América Rosalba Vázquez-Olmos, Alejandro Luis Vega-Jiménez, Blanca Paz-Díaz

structures. Materials Science in Semiconductor Processing, 21: 154-160.

https://doi.org/10.1016/j.mssp.2014.01.006

Jin, T., He, Y. (2011). Antibacterial activities of magnesium oxide (MgO) nanoparticles against foodborne pathogens. Journal of Nanoparticle Research, 13(12): 6877-6885. https://doi.org/10.1007/s11051-011-0595-5

Kaftelen, H., Ocakoglu, K., Thomann, R., Tu, S., Weber, S., Erdem, E. (2012). EPR and photoluminescence spectroscopy studies on the defect structure of $\mathrm{ZnO}$ nanocrystals. Physical Review B, 86(1): 014113.

https://doi.org/10.1103/PhysRevB.86.014113

Kalyani, R. L., Venkatraju, J., Kollu, P., Rao, N. H., Pammi, S. V. N. (2015). Low temperature synthesis of various transition metal oxides and their antibacterial activity against multidrug resistance bacterial pathogens. Korean Journal of Chemical Engineering, 32(5): 911-916. https://doi.org/10.1007/s11814-014-0262-5

Katwal, R., Kaur, H., Sharma, G., Naushad, M., Pathania, D. (2015). Electrochemical synthesized copper oxide nanoparticles for enhanced photocatalytic and antimicrobial activity. Journal of Industrial and Engineering Chemistry, 31: 173-184. https://doi.org/10.1016/j.jiec.2015.06.021

Kefeni, K. K., Mamba, B. B., Msagati, T. A. (2017). Application of spinel ferrite nanoparticles in water and wastewater treatment: A review. Separation and Purification Technology, 188:399-422. https://doi.org/10.1016/j.seppur.2017.07.015

Krishnamoorthy, K., Manivannan, G., Kim, S. J., Jeyasubramanian, K., Premanathan, M. (2012). Antibacterial activity of MgO nanoparticles based on lipid peroxidation by oxygen vacancy. Journal of Nanoparticle Research, 14(9): 1063. https://doi.org/10.1007/s11051-012-1063-6

Król, A., Pomastowski, P., Rafińska, K., Railean-Plugaru, V., Buszewski, B. (2017). Zinc oxide nanoparticles: Synthesis, antiseptic activity and toxicity mechanism. Advances in Colloid and Interface Science. https://doi.org/10.1016/j.cis.2017.07.033

Lemire, J. A., Harrison, J. J., Turner, R. J. (2013). Antimicrobial activity of metals: mechanisms, molecular targets and applications. Nature Reviews Microbiology, 11(6): 371. https://doi.org/10.1038/nrmicro3028

Mamonova, I., Babushkina, I., Norkin, I., Gladkova, E., Matasov, M., Puchin'yan, D. (2015). Biological activity of metal nanoparticles and their oxides and their effect on bacterial cells. Nanotechnologies in Russia, 10(1-2): 128-134. https://doi.org/10.1134/S1995078015010139

Mandal, S., Natarajan, S., Tamilselvi, A., Mayadevi, S. (2016). Photocatalytic and antimicrobial activities of zinc ferrite nanoparticles synthesized through soft chemical route: A magnetically recyclable catalyst for water/wastewatertreatment. Journal of Environmental Chemical Engineering, 4(3): 2706-2712. https://doi.org/10.1016/j.jece.2016.05.020

Muthukumar, H., Chandrasekaran, N. I., Mohammed, S. N., Pichiah, S., Manickam, M. (2017). Iron oxide nano-material: Physicochemical traits and in vitro antibacterial propensity against multidrug resistant bacteria. Journal of Industrial and Engineering Chemistry, 45: 121-130. https://doi.org/10.1016/j.jiec.2016.09.014

Prado, V., Vidal, R., Durán, C. (2012). Aplicación de la capacidad bactericida del cobre 
en la práctica médica. Revista médica de Chile, 140(10): 1325-1332.

https://doi.org/10.4067/S0034-98872012001000014

Raghunath, A., Perumal, E. (2017). Metal oxide nanoparticles as antimicrobial agents: A promise for the future. International journal of antimicrobial agents, 49(2): 137-152. https://doi.org/10.1016/j.ijantimicag.2016.11.011

Rankin, D. W. (2009). CRC handbook of chemistry and physics, David R. Lide (ed.): Taylor \& Francis.

Rufus, A., Sreeju, N., Philip, D. (2016). Synthesis of biogenic hematite $\left(\alpha-\mathrm{Fe}_{2} \mathrm{O}_{3}\right)$ nanoparticles for antibacterial and nanofluid applications. RSC Advances, 6(96): 94206-94217. https://doi.org/10.1039/C6RA20240C

Santhoshkumar, J., Kumar, S. V., Rajeshkumar, S. (2017). Synthesis of zinc oxide nanoparticles using plant leaf extract against urinary tract infection pathogen. Resource-Efficient Technologies, 3(4): 459-465.

https://doi.org/10.1016/j.reffit.2017.05.001

Sawai, J., Kojima, H., Igarashi, H., Hashimoto, A., Shoji, S., Sawaki, T. et al. (2000). Antibacterial characteristics of magnesium oxide powder. World Journal of MicrobiologyandBiotechnology,16(2):187-194.https://doi.org/10.1023/A:1008916209784

Sawai, J. (2003). Quantitative evaluation of antibacterial activities of metallic oxide powders $(\mathrm{ZnO}, \mathrm{MgO}$ and $\mathrm{CaO})$ by conductimetric assay. Journal of microbiological methods, 54(2): 177-182. https://doi.org/10.1016/s0167-7012(03)00037-x

Sawai, J., Yoshikawa, T. (2004). Quantitative evaluation of antifungal activity of metallic oxide powders ( $\mathrm{MgO}, \mathrm{CaO}$ and $\mathrm{ZnO}$ ) by an indirect conductimetric assay. Journal of applied microbiology, 96(4): 803-809.

https://doi.org/10.1111/j.1365-2672.2004.02234.x

Stankic, S., Suman, S., Haque, F., Vidic, J. (2016). Pure and multi metal oxide nanoparticles: Synthesis, antibacterial and cytotoxic properties. Journal of nanobiotechnology, 14(1): 73. https://doi.org/10.1186/s12951-016-0225-6

Tadic, M., Kopanja, L., Panjan, M., Kralj, S., Nikodinovic-Runic, J., Stojanovic, Z. (2017). Synthesis of core-shell hematite $\left(\alpha-\mathrm{Fe}_{2} \mathrm{O}_{3}\right)$ nanoplates: Quantitative analysis of the particle structure and shape, high coercivity and low cytotoxicity. Applied Surface Science, 403: 628-634. https://doi.org/10.1016/j.apsusc.2017.01.115

Vázquez-Olmos, A., Ramos-Bautista, A., Fern, A., Sato-Berru, R. (2008). $\mathrm{Co}_{3} \mathrm{O}_{4}$ and $\mathrm{CuO}$ nanoparticles obtained by a solvent-free method. Nano Science \& Nano Technology: An Indian Journal, 2(1).

Vázquez-Olmos, A., Redón, R., Fernández-Osorio, A., Saniger, J. (2005a). Roomtemperature synthesis of $\mathrm{Mn}_{3} \mathrm{O}_{4}$ nanorods. Applied Physics A: Materials Science \& Processing, 81(6): 1131-1134. https://doi.org/10.1007/s00339-005-3291-4

Vázquez-Olmos, A., Redón, R., Rodríguez-Gattorno, G., Mata-Zamora, M. E., Morales-Leal, F., Fernández-Osorio, A. L. et al. (2005b). One-step synthesis of Mn 3 O 4 nanoparticles: Structural and magnetic study. Journal of colloid and interface science, 291(1): 175-180. https://doi.org/10.1016/j.jcis.2005.05.005

Vázquez-Olmos, A., Redón, R., Fernández-Osorio, A., Sato-Berrú, R., Saniger, J. (2016). CuO nanoparticles with PAMAM dendrimers. Journal of Coordination Chemistry, 69(6): 1039-1049. https://doi.org/10.1080/00958972.2016.1153079 
Vázquez-Olmos, A. R., Gómez-Peralta, J. I., Sato-Berru, R. Y., Fernández-Osorio, A. L. (2014). Diluted magnetic semiconductors based on Mn-doped In ${ }_{2} \mathrm{O}_{3}$ nanoparticles. Journal of Alloys and Compounds, 615: S522-S525. https://doi.org/10.1016/j.jallcom.2014.01.085

Velasco-Arias, D., Díaz, D., Santiago-Jacinto, P., Rodríguez-Gattorno, G., VázquezOlmos, A., Castillo-Blum, S. (2008). Direct interaction of colloidal nanostructured $\mathrm{ZnO}$ and $\mathrm{SnO}_{2}$ with $\mathrm{NO}$ and $\mathrm{SO}_{2}$. Journal of nanoscience and nanotechnology, 8(12): 6389-6397.

Vincent, M., Hartemann, P., Engels-Deutsch, M. (2016). Antimicrobial applications of copper. International journal of hygiene and environmental health, 219(7): 585-591. https://doi.org/10.1016/j.ijheh.2016.06.003

Wang, L., Hu, C., Shao, L. (2017). The antimicrobial activity of nanoparticles: Present situation and prospects for the future. International journal of nanomedicine, 12: 1227.

Wang, Z. L. (2004). Nanostructures of zinc oxide. Materials today, 7(6): 26-33. https://doi.org/10.2147/IJN.S121956

Wen-da, W., Yu, Z., Yue-xin, C. (2016). Stenting for chronic obstructive venous disease: A current comprehensive meta-analysis and systematic review. Phlebology, 31(6): 376-389. https://doi.org/10.1177/0268355515596474

World Health Organization (2018). Antimicrobial resistance. http://www.who.int/ mediacentre/factsheets/fs194/en/ (Consultado, 15 de febrero, 2018).

Yamamoto, O., Ohira, T., Alvarez, K., Fukuda, M. (2010). Antibacterial characteristics of $\mathrm{CaCO}_{3}-\mathrm{MgO}$ composites. Materials Science and Engineering: B, 173(1): 208-212. https://doi.org/10.1016/j.mseb.2009.12.007

Zhu, L., Basnet, P., Larson, S. R., Jones, L. P., Howe, J. Y., Tripp, R. A. et al. (2016). Visible light-induced photoeletrochemical and antimicrobial properties of hierarchical $\mathrm{CuBi}_{2} \mathrm{O}_{4}$ by facile hydrothermal synthesis. ChemistrySelect, 1(8): 1518-1524. https://doi.org/10.1002/slct.201600164 